\title{
International Exchange Program with China: The First-Year Experience of Engineering Technology Students
}

\author{
Daniel K. Jones ${ }^{1}$, Albert Peng ${ }^{2}$, and Tina M. Moreau-Jones ${ }^{3}$ \\ ${ }^{1}$ Department of Mechanical and Industrial Engineering Technology, Institute of Technology, \\ State University of New York, Utica, NY 13504 \\ ${ }^{2}$ Department of Industrial and Engineering Technology, Central Michigan University, Mt. \\ Pleasant, MI 48859 \\ ${ }^{3}$ United States Catholic Mission Association, Catholic Network of Volunteer Service, and \\ Saint Vincent Pallotti Center, Washington, DC 20009
}

\section{Introduction}

In May, 2001, engineering technology students from Central Michigan University (CMU) traveled to North China University of Technology (NCUT) in Beijing, China. This first -year delegation consisted of fourteen CMU students, two professors, and one chaperone. The delegation spent most of the time in group activities, which included tours of industry and NCUT laboratories and lectures by NCUT faculty.

The technical content of this trip focused on manufacturing, computer applications, and mechanical design. Students also gained significant exposure to non-technical aspects of life in China. The CMU delegation attended lectures and exhibits related to Chinese culture, history, architecture, music, and art.

\section{Background}

Recent changes in China have encouraged open relationships with other countries. Now, more than ever, universities in the U.S. and China are eager to learn from each other. Before establishing this new program, a CMU faculty member traveled to various universities in China. NCUT was selected for this program because of its emphasis on technology and its prior experience in international exchanges with Japan, Germany, and the United States.

A year before the initial trip, faculty at CMU and NCUT agreed to establish the exchange program and formalize the process. CMU faculty worked closely with the CMU Office of International Education (OIE), and the course content was approved by the usual curricular process. After six months of correspondence, primarily through email, a detailed itinerary was planned for the first CMU visit to NCUT. 


\section{Academic Aspects}

Advanced planning was crucial to the success of the trip. Advertisement for the course began several months before the trip. Posters and in-class announcements proved to be very effective at generating student interest. All of the fourteen interested students were able to make the trip. Eleven of these students majored in engineering technology, and one student majored in each of the following areas: computer science, industrial education, and industrial technology management.

CMU students earned three credits for successful completion of the exchange program. This fulfilled requirements for a technical core course as well as a humanities/social science elective. Students registered for the course, IET 420C, during the first summer session. The course began with bi-weekly orientation sessions one month prior to departure. The content of the course is outlined below.

A. Orientation to International Technology

1. Chinese Culture Considerations

2. Chinese Language Considerations

3. History and Background of China

4. Guest Speakers

5. Packing and Traveling

6. Establishing Communications with Host Student

B. On-Site Visit to China

1. Lectures on the Culture/History of China

2. Chinese Language Instruction

3. NCUT Laboratory Tour

4. Industry Plant Tours

5. Oral Presentations by NCUT Faculty and Students

6. Visitation to Historical Sites

7. Maintenance of a Daily Journal

8. Student-to-Student Exchange

C. Follow-up after the Trip

1. Debriefing and Review

2. Presentations to CMU and Civic Groups

3. Participation and Help with NCUT Exchange Visit 
Evaluation of the students' performance for this course included the following:

\begin{tabular}{|l|r|}
\hline Topic & $\begin{array}{l}\text { Portion of } \\
\text { Grade (\%) }\end{array}$ \\
\hline Pre-trip Preparation & 15 \\
\hline Performance in China and Journal Report & 75 \\
\hline Post-trip Activities & 10 \\
\hline Total & 100 \\
\hline
\end{tabular}

\section{Before the Trip}

Each individual student was encouraged to obtain a passport two months in advance. Photocopies of the passports for the entire group were required to obtain travel visas for ea ch member of the delegation. The CMU Office of International Education (OIE) served as the official point of contact during travel. The OIE was available 24 hours a day in case of emergency. Faculty gathered names and phone numbers of contact people in the US in case of emergency, and a copy was left with the CMU OIE. A phone chain was established to verify safe arrival in China.

Pre-travel orientation sessions gave students an overview of the trip and the opportunity to meet fellow delegates. Students were given handouts on Chinese culture, ${ }^{1}$ travel tips, ${ }^{2,3}$ and health information. ${ }^{4}$ Two students from China, studying at CMU, gave suggestions, and they were available to answer questions. The OIE provided all students with a travel brochure containing general information on international travel. ${ }^{5}$ Basic travel information, such as a list of items to pack, was also discussed because some of the students were novice travelers.

\section{During the Trip}

NCUT provided accommodations in hotel rooms and transportation for off-campus activities. Most of the meals were served in the campus dining facilities. Throughout the journey, the delegation enjoyed an abundance of food, served in traditional fashion with multiple courses and chop-sticks. The CMU delegation called the CMU OIE on a regular basis to confirm that the trip was running smoothly.

CMU students paired up with NCUT host students, who spoke English fluently. The pairing of exchange students allowed them to meet informally, to socialize and to learn about each other's lives. The NCUT host students provided much insight during tours of the campus and historical sites.

Faculty and staff provided tours of the NCUT campus, including classrooms, the library, the manufacturing laboratory, the mechanical engineering research laboratory, and computer facilities. NCUT faculty provided lectures in English to CMU students in a wide range of topics, including culture, language, Chinese dynasties, ancient architecture, traditional art, and music.

Daily trips off campus gave CMU students exposure to many aspects of life in Beijing. The group visited historical sites, including the Forbidden City, the Great Wall, Tiananmen Square, 
Ming Tomb, Summer Palace, and the Temple of Heaven. Students also attended a tour and lectures at Rockwell Automation Research Center. Bus trips to each of these destinations were very informative, giving the delegation glimpses of traffic, massive apartment complexes, and urban life in Beijing.

Leisure activities included a tour of Beihai Park, an acrobat show, and a music concert of traditional Chinese instruments. CMU students traveled on public busses and subways, and they shopped at famous commercial areas in Beijing. Small groups attended a traditional dumpling dinner in the homes of professors who had apartments on campus. Social activities included a basketball game, talent show, dance, and farewell party. At the end of the trip, CMU and NCUT partners exchanged gifts as tokens of appreciation.

\section{After the Trip}

While traveling, students were responsible for maintenance of a daily journal. After returning to the US, students wrote individual final reports, which included journal entries, photographs, and reflections on their experiences. The group of CMU students met to reflect on their experiences. Students who received scholarships for travel were responsible for presentations to CMU and civic groups, as well as participation in a future NCUT visit to CMU. Some of the CMU and NCUT students continue to correspond via email.

As a continuation of the exchange program, NCUT faculty plan to travel to the US for professional development. Most of the time will be spent conducting research, teaching at CMU, and touring industries throughout the state of Michigan. Details are still pending; delays resulted from a CMU faculty sabbatical. Travel restrictions have resulted from recent world events, and two NCUT faculty members were not able to obtain visas. However, NCUT's Vice President and the Director of International Education visited CMU in January 2002 to strengthen the current ties and explore future opportunities. The NCUT delegates met with CMU's Provost, Deans, Chairs, students, and faculty members.

\section{What We Learned}

The leader of the delegation was fluent in Chinese and English. This was vital to the successful development of the program, particularly during the early phases. The other members of the delegation could not understand the Chinese language. Most of the students, professors, and merchants encountered were quite fluent in English, and so communication did not pose a significant barrier. The CMU delegation was very impressed with their experience in China. Beijing proved to be an incredible city with a rich history and a deep appreciation for culture.

CMU students repeatedly mentioned how NCUT students were very dedicated to their education. They viewed their education as a privilege, not to be taken for granted. During our visit, they attended classes on Saturday and Sunday. Most of the CMU students admitted that their Chinese counterparts studied much harder than students in the US. NCUT students frequently spoke of how highly the Chinese value the opportunity for education. CMU students and faculty found that higher education is considered much more of a privilege in China, whereas in the US, college tends to be taken for granted. 
Several CMU students commented that they learned much more than they would have from a conventional 3-credit course. After returning to the US and reflecting on their experience, the comments from CMU students were remarkable. In their final journal reports, students made the following comments:

O "This trip had a profound impact on my life, and my inner peace is better than it ever has been. I would just like to thank everybody that was involved in putting it together. If OIE needs any of my help to recruit students, I would love to help in any way that I could."

o "It was a trip that I will never forget. I had a great time and am very thankful for the opportunity of a lifetime. The trip was well planned and went off without a hitch. I couldn't have asked for anything more."

○ "This was hands down the best class that I have had and probably the best I will ever have."

○ "I am very glad to not have missed the opportunity. I strongly urge anyone with such an opportunity to take advantage of it. There is so much to be gained from such a trip. But, hey, go see for yourself."

o "This experience was something I will never forget. I learned so much more than a typical class could ever teach me in college."

○ "My view of the world around me has changed. I don't see things in the same way as before."

\section{Recommendations for Improvements}

In the early stages of this program, the content is being developed, revised, and expanded. The learning from this cross-cultural experience will contribute to future program development. In light of the first trip, several changes are recommended. Everyone would have benefited from more delegate interaction before the trip. More advance training would help to better prepare some of the students for international travel. Although students were encouraged to read the information provided by the OIE, a test before the trip may have helped to motivate students to study the material more thoroughly.

Students should be encouraged to learn as much as possible before the trip about language, culture, and the importance of the long history of China. In particular, the delegation would have benefited from cultural awareness training from a qualified instructor. Other items of concern are presented in the following list.

$\circ$ Realize that a large portion of Chinese citizens understand English. They understand many of the comments made by students. 
- Avoid vulgar language and be careful with conversations that may be interpreted as disrespectful.

- Do not discuss politics. Asking political questions of NCUT students puts them on the spot.

- Conservative attire is appropriate. Women should not wear sleeveless shirts, despite the hot climate.

- It is important that individuals inform others when leaving the group. A student left campus at night alone, causing concern among fellow-students, hosts, and campus security.

- Valuables should be stored of to avoid theft. Do not show off laptop computers and expensive cameras.

○ Provide daily time for journal writing.

When traveling by bus, the size of the delegation should be given further consideration. With fourteen students, three chaperones, and a tour guide, the NCUT bus was not large enough. In the future, the size of the group should be limited to 12 students. Otherwise, accommodations should be made for a larger bus or an additional vehicle.

\section{Future Plans}

Based on the success of the initial exchange, this program is likely to continue for many years. The itinerary of future trips will evolve from what was learned about the unique culture, technology, and academic life in China. The second CMU delegation plans to visit Beijing in May 2002. The group will consist of one faculty member and nine students. Although the delegation will be smaller, the trip will be very similar to the initial visit.

Travel restrictions and delays have resulted from crisis on September 11, postponing the anticipated visits of NCUT faculty to the US. In the Fall of 2002, an NCUT dean and president plan to visit CMU to make future arrangements for NCUT faculty to teach and conduct research at CMU. Although there is potential for graduate students from China to study in the US, it does not appear that undergraduate students will have this opportunity in the near future.

As an unexpected outcome, this initial exchange has served as a seed program for future expansion. NCUT is now interested in expanding the exchange program into other disciplines, such as business and mathematics.

\section{Conclusion}

Students and faculty from the US and China have much to learn from each other. With a common interest in technology, the US and China will continue mutually beneficial academic exchange programs.

The initial trip to Beijing had a tremendous impact on the CMU students and faculty. Most of the CMU students, who grew up in suburban neighborhoods, were exposed to a foreign metropolitan city. After this cultural immersion in China, students now have a greater appreciation for diverse cultures and an understanding of ancient history. This experience was 
particularly valuable for students in engineering technology. CMU students were generally shocked at the dedication of NCUT students to their studies. Some of the CMU students, realizing that students in China work so hard, now have a better appreciation of their education. Everyone who participated in this program now looks at the world differently.

\section{Acknowledgements}

The faculty, staff, and administrators at NCUT worked very hard to make this exchange a success. Wang Baoquan, NCUT Director of International Education, provided valuable assistance with travel arrangements and accommodations, as well as contacts with NCUT faculty and administrators. The authors would like to thank NCUT Vice President Xiang Jin and Professors Zhang Changnian, Chen Ching, Liu Jiying, Chen Qin, Zhu Shenpeng, and others for their hospitality and insightful lectures.

\section{Bibliographic Information}

${ }^{1}$ Culturgram 2000: People's Republic of China, Bringham Young University and eMSTAR, Inc. 1999.

${ }^{2}$ Travellers Tips to China, Tiglion Consultancy Co. Ltd., July 1999, www.tiglioncom/travel/china.

${ }^{3}$ China Consular Information Sheet, http://travel.state.gov/china.html, December 2000.

${ }^{4} \mathrm{CDC}$ Health Information for Travelers to East Asia, Center for Disease Control, www.cdc.gov/cgi-bin/sendit.exe, April 2001.

${ }^{5}$ Study Abroad Handbook, Office of International Education, Central Michigan University, Summer/Fall Semester 2001.

\section{Biographical Information}

DANIEL K. JONES, Ph.D., P.E., is currently an assistant professor at the SUNY Institute of Technology in Utica, NY. He received a Ph.D. in Engineering from the University of Pittsburgh, and B.S. and M.S. degrees in Mechanical Engineering from Pennsylvania State University. Dr. Jones served as a co-faculty member for the course and traveled with the delegation to China. He is a member of ASME, ASEE, SAE, and SME.

ALBERT PENG, Ph.D., is currently a professor in the Department of Industrial and Engineering Technology at Central Michigan University. He received M.S. and Ph.D. degrees from Case Western Reserve University in Cleveland, Ohio. Dr. Peng was the primary motivator for the exchange program, which he has been developing for almost two years. In addition to leading the delegation, Dr. Peng served the vital role of translator.

TINA M. MOREAU-JONES, M.A., is currently a research consultant for United States Catholic Mission Association in Washington, D.C. She received a M.A. degree from Catholic Theological Union in Chicago. Mrs. Moreau-Jones has lead seven annual student delegations to El Salvador and Haiti. She has taught and worked in the United States and Bolivia. Mrs. Moreau-Jones served as a chaperone for the delegation to China. 